\title{
The knowledge, attitude $\&$ behaviour on neonatal jaundice of postnatal mothers in Provincial General Hospital, Badulla
}

\author{
B K N R Rodrigo ${ }^{1}$, Gayan Cooray ${ }^{2}$ \\ Sri Lanka Journal of Child Health, 2011; 40(4): 164-168
}

\begin{abstract}
Objectives: To determine the knowledge, attitude \& behaviour on neonatal jaundice of postnatal mothers in Provincial General Hospital (PGH), Badulla.
\end{abstract}

Method: In this observational cross-sectional study, 396 mothers, who delivered at PGH Badulla from $1^{\text {st }}$ May 2010 to $15^{\text {th }}$ June 2010 , were interviewed using a structured questionnaire. The questionnaire was used to assess the participant's knowledge, attitude and behaviour on neonatal jaundice.

Results: The mean knowledge score was $31 \pm 14$, the mean attitude score $65.7 \pm 20.6$ and the mean behaviour score $66.1 \pm 18.8$. Ethnicity, level of education and previous experience with neonatal jaundice showed a significant association with the knowledge score.

Conclusions: The knowledge of neonatal jaundice among postnatal mothers was low. There was significant correlation between mothers' attitude and behaviour scores with the knowledge scores.

(Key Words: Neonatal jaundice, postnatal mothers)

\section{Introduction}

Neonatal jaundice is a common condition that paediatricians encounter in their practice. It is also a significant cause of neonatal morbidity world-wide and is estimated to be present in $60 \%$ of term neonates and $80 \%$ of preterm babies ${ }^{1,2}$. Intervention to prevent progression of neonatal jaundice significantly reduces the morbidity and mortality due to this condition ${ }^{3}$. Since babies and mothers are discharged early, the ability of the mothers to recognize neonatal jaundice becomes important. In Sri Lanka, there is little information about the knowledge, attitude \& behaviour on neonatal jaundice of postnatal mothers.

${ }^{1}$ Acting Paediatrician, ${ }^{2}$ Senior House Officer,
Provincial General Hospital, Badulla

(Received on 24 September 2010: Accepted on 17 December 2010)

\section{General Objective}

To determine the knowledge, attitude \& behaviour on neonatal jaundice of postnatal mothers in Provincial General Hospital, Badulla

\section{Specific objectives}

1. To study the socio-demographic background of the study population, such as age, educational level, occupation and residential area.

2. To assess knowledge, behaviour and attitude on neonatal jaundice using an appropriate scoring system.

3. To see whether there is a significant correlation in the knowledge, attitude \& behaviour on neonatal jaundice in the study population.

\section{Method}

An observational cross-sectional study was conducted by interviewer-administered structured questionnaire from $1^{\text {st }}$ May to $15^{\text {th }}$ June 2010 in the postnatal wards of Provincial General Hospital (PGH) Badulla. The study population comprised all postnatal mothers during the six week study period. Severely ill mothers, those transferred within 48 hours of filling the questionnaire, mentally subnormal mothers and mothers who had not given consent for the study were excluded.

A pilot study was carried out for a one week period using the same setting and questionnaire to assess the feasibility of the study and drawbacks of the questionnaire. A structured intervieweradministered questionnaire was formulated in English for collection of data and translated into Sinhala and Tamil. The questionnaire consisted of four parts recording information on sociodemographic data of the mother and information related to the mother's knowledge, attitude, and behaviour.

Informed written consent was obtained from all mothers who participated in the study. For illiterate mothers, questionnaire and consent forms were read out carefully and clearly, prior to the study. Ethical clearance for the study was obtained from the Ethical Review Committee of Uva Clinical Society, Badulla. 


\section{Results}

During the study period a total of 396 mothers were interviewed within 48 hours of delivery using the structured questionnaire. The data was analyzed using SPSS Version 17 \& SAS 9.0 statistical packages. Marks for each question were allocated according to the different weight of the questions (e.g. more marks for questions related to danger signs and basic knowledge). Scoring system was finalized after discussing with panel of specialities which included three consultant paediatricians.

Mothers' demographic characteristics are shown in Table 1 .

Table 1

Mothers' demographic characteristics $(n=384)$

\begin{tabular}{|l|c|}
\hline \multicolumn{1}{|c|}{ Characteristic } & Percentage \\
\hline \multicolumn{1}{|c|}{$\begin{array}{c}\text { Age (years) } 20-24 \\
\text { 25-35 }\end{array}$} & 04.2 \\
30-34 & 23.7 \\
Mother's occupation & 35.7 \\
Education (teachers) & 22.7 \\
Nurses, midwives & 13.8 \\
Healthcare support (labourers) & 08.9 \\
Manual labourers & 01.0 \\
House wives & 01.3 \\
Clerks and office support & 02.3 \\
Farming & 73.2 \\
\hline Place of residence & 04.2 \\
City & 09.1 \\
Rural & \\
Estate & 22.1 \\
\hline Ethnicity & 69.0 \\
Sinhala & 08.9 \\
Tamil & \\
Muslim & 77.6 \\
\hline Parity of the mother & 18.8 \\
Primi & 03.6 \\
Multi & 41.7 \\
\hline
\end{tabular}

Description of the study population by the knowledge score

The knowledge score was categorized into 3 groups as follows: $0-33=10 \mathrm{w}, 34-66=$ moderate and $67-$ $100=$ high. The mean knowledge score was $31 \pm 14$. About $53 \%$ of mothers $[\mathrm{n}=203]$ had a low level of knowledge about neonatal jaundice. Knowledge score according to various maternal factors is shown in table 2 .
Table 2

Knowledge score by maternal factors

\begin{tabular}{|l|c|}
\hline \multicolumn{1}{|c|}{ Maternal factor } & $\begin{array}{c}\text { Mean } \\
\text { score }\end{array}$ \\
\hline Occupation & \\
Education (teachers) & 42.9 \\
Nurses, Midwives & 54.3 \\
Healthcare Support (labourers) & 36.8 \\
Manual labourers & 20.0 \\
House wives & 32.0 \\
Clerks and office support & 39.1 \\
Farming & 19.7 \\
\hline Ethnicity & \\
Sinhala & 35.0 \\
Tamil & 20.9 \\
Muslim & 30.5 \\
\hline Place of residence & \\
City & 38.7 \\
Rural & 32.0 \\
Estate & 17.5 \\
\hline Educational level & \\
No schooling & 13.0 \\
Primary school & 24.4 \\
Ordinary level (OL) & 30.1 \\
Advanced level (AL) & 39.6 \\
University & 46.5 \\
\hline Previous sibling with jaundice & \\
Yes & 41.3 \\
No & 31.1 \\
\hline
\end{tabular}

Mothers whose occupations were 'Manual labourers' and 'Farming' scored lower marks than other categories $(\mathrm{P}<0.01)$. Tamil mothers were less knowledgeable about jaundice than Sinhala and Muslim mothers $(\mathrm{P}<0.05)$. Mothers residing in cities had higher knowledge than rural or estate mothers $(\mathrm{P}<0.01)$. Mothers with no or only primary school education scored lower marks than other categories $(\mathrm{P}<0.001)$. There was, however, no difference between the university level group and AL-OL group. $(\mathrm{P}>0.05)$

\section{Description of the study population by attitude score}

The attitude score was categorized into 3 groups as follows: 0-33-low, 33-66-moderate, 66-100-high. The mean attitude score was $65.7 \pm 20.6$. About $55 \%$ of mothers had a high level of attitude about neonatal jaundice. Attitude score according to various maternal factors is shown in table 3 . 
Table 3

Attitude score by maternal factors

\begin{tabular}{|l|c|}
\hline \multicolumn{1}{|c|}{ Maternal factor } & Mean score \\
\hline Occupation & 76.2 \\
Education (teachers) & 85.0 \\
Nurses, Midwives & 73.0 \\
Healthcare Support (labourers) & 54.4 \\
Manual labourers & 65.1 \\
House wives & 72.8 \\
Clerks and office support & 56.4 \\
Farming & \\
\hline Ethnicity & 68.1 \\
Sinhala & 55.9 \\
Tamil & 64.3 \\
Muslim & 72.2 \\
\hline Place of residence & 65.3 \\
City & 52.9 \\
Rural & \\
Estate & 52.0 \\
\hline Educational level & 61.4 \\
No schooling & 64.7 \\
Primary school & 71.2 \\
Ordinary level (OL) & 78.7 \\
Advanced level (AL) & 76.4 \\
University & 65.0 \\
\hline Previous sibling with jaundice & \\
Yes & \\
No & \\
\hline
\end{tabular}

There were statistically significant low scores in 'manual labourers' and 'farming' categories compared to other groups $(\mathrm{P}<0.05)$. Tamil mothers showed significantly low scores with respect to attitude $(\mathrm{P}<0.001)$. A statistically significant high attitude score was noticed in 'previous sibling with jaundice' group $(\mathrm{P}<0.05)$.

\section{Description of the study population by behaviour score}

The behaviour score was categorized into 3 groups as follows: 0-33: low/33-66: moderate / 66-100: high. The mean behaviour score was $66.1 \pm 18.8$. About $56 \%$ of mothers [ $n=216]$ had high level of behaviour about neonatal jaundice. Behaviour score according to various maternal factors is shown in table 4.

The highest behaviour score (83.8) was obtained by 'Nurses-Midwives' and the lowest (56.8) by 'Manual labourers'.. Behaviour scores were more or less similar in the Sinhala and the Muslim mothers. Tamil mothers showed significantly lower scores (P $<0.01)$. Estate and rural mothers had scores significantly lower than that of urban mothers ( $\mathrm{P}$ $<0.001)$. Primary school and no schooling groups had scores significantly lower than others $(\mathrm{P}<0.01)$.
A higher score of 76.6 was obtained by mothers who had previous experience with a baby with jaundice and this was statistically significant ( $P$ $<0.01)$.

Table 4

Behaviour score by maternal factors

\begin{tabular}{|l|c|}
\hline \multicolumn{1}{|c|}{ Maternal factor } & Mean score \\
\hline Occupation & 75.0 \\
Education (teachers) & 83.8 \\
Nurses, Midwives & 73.0 \\
Healthcare Support (labourers) & 56.8 \\
Manual labourers & 65.5 \\
House wives & 71.6 \\
Clerks and office support & 59.4 \\
Farming & \\
\hline Ethnicity & 68.0 \\
Sinhala & 58.5 \\
Tamil & 64.7 \\
Muslim & \\
\hline Place of residence & 72.0 \\
City & 65.6 \\
Rural & 55.8 \\
Estate & \\
\hline Educational level & 52.0 \\
No schooling & 61.4 \\
Primary school & 64.7 \\
Ordinary level (OL) & 71.2 \\
Advanced level (AL) & 78.7 \\
University & 76.6 \\
\hline Previous sibling with jaundice & 65.4 \\
Yes & \\
No & \\
\hline
\end{tabular}

Almost all the mothers $(n=379)$ had no exposure with a sibling with complication due to jaundice and there was no significant difference between them ( $\mathrm{P}$ $>0.05)$.

Nearly two thirds of the respondents $(n=254)$ indicated the antenatal clinic as the major source of their information about neonatal jaundice and 20\% declared that they got information through pregnant mothers.

Approximately $80 \%$ of mothers $(n=305)$ declared that they would show the baby to a doctor if the baby is jaundiced and only $0.5 \%$ mothers $(n=2)$ stated that the baby will be observed at home. A total of $54 \%$ mothers $(n=207)$ indicated that they were worried about blood being taken from baby due to pain.

There was a significant correlation between attitude and behaviour scores of mothers on neonatal jaundice ( $\mathrm{R}$ square=61.7). There was also a significant correlation between the attitude score and the knowledge score (R square=67.5). 


\section{Discussion}

The present study revealed inadequate knowledge of neonatal jaundice among postnatal mothers (mean knowledge score $31 \pm 14$ ). Mothers who were manual labourers \& involved in farming were less knowledgeable about neonatal jaundice than other categories $(p<0.01)$. Tamil mothers had lower knowledge scores than Sinhala and Muslim mothers $(\mathrm{P}<0.05)$. Mothers residing in cities had higher knowledge than estate or rural mothers $(\mathrm{P}<0.01)$. Mothers with no or only primary school level education scored lower marks than those with higher education $(\mathrm{P}<0.0001)$. However, there was no significant difference between the University group and the AL group $(\mathrm{P}>0.05)$.

The level of attitude about neonatal jaundice among postnatal mothers was satisfactory (mean attitude score $65.7 \pm 20.6$ ). Mothers who were manual labourers \& farmers had lower attitude scores than other categories $(p<0.05)$. Tamil mothers had lower attitude scores than Sinhala and Muslim mothers $(\mathrm{P}<0.01)$. Mothers who had previous experience with a jaundiced baby had significantly higher attitude scores than those with no such experience $(\mathrm{P}<0.05)$.

The level of behaviour about neonatal jaundice among postnatal mothers was moderately satisfactory (mean behaviour score $66.1 \pm 18.8$ ). Estate and rural mothers had significantly lower behaviour scores than urban mothers $(\mathrm{P}<0.0001)$. Tamil mothers had lower behaviour scores than Sinhala and Muslim mothers $(\mathrm{P}<0.01)$. Mothers with no or only primary school education scored lower marks than those with higher education $(\mathrm{P}<0.01)$. Mothers who had previous experience with a jaundiced baby had significantly higher behaviour scores than those with no such experience $(\mathrm{P}<0.01)$.

The main source of information about jaundice was the antenatal clinic. Nearly two thirds of the respondents $(n=254)$ indicated it. In our study almost all the mothers were attending antenatal clinic indicating best coverage.

A study in Nigeria $^{4}$ community health workers indicated $75.8 \%$ had knowledge about all three locations for observing jaundice (yellow discolouration of the skin, eyes and palms and soles) of neonatal jaundice. In our study, majority indicated only one location [yellow discolouration of the skin] for jaundice. No respondents gave more than one location for jaundice. Knowledge about jaundice as yellow discolouration of the skin was $43 \%(n=167)$.
Our results showed limited knowledge about the causes of jaundice similar to the Indian study ${ }^{5}$. In our study, about $55 \%$ of mothers $(n=211)$ thought that reduced breast milk was a cause for neonatal jaundice. None knew prematurity and physiological jaundice as causes. Most of the mothers $(n=218)$ in our study were given one cause for jaundice. Similarly, Hannon and colleagues have reported 55\% Spanish and English speaking respondents who had connected the breast feeding to the neonatal jaundice ${ }^{8}$.

A large population of mothers had a weak knowledge about the complications of jaundice while complications like mental handicap $(n=21$, $5.4 \%)$ and neonatal death $(n=25,6.5 \%)$ were known by a very small percentage in our study. This could have an influence on perceived severity of jaundice and consequently on the steps taken.

In our study about $32 \%(n=124)$ knew about the best technique for diagnosis of neonatal jaundice. Surprisingly majority of the population had no idea of diagnostic method for neonatal jaundice.

About $44 \%$ mothers $(n=171)$ were aware of phototherapy as a standard treatment for neonatal jaundice. In our study about $14.2 \% \quad(n=55)$ were aware of exchange transfusion as a treatment for jaundice. Majority among them were mothers who are working in the health sector. A study which was done by Ogunfowora and Danial ${ }^{4}$ has also justified phototherapy and exchange transfusion remained the standard treatment of neonatal jaundice.

Maternal attitude and behaviour towards neonatal jaundice is satisfactory, being not comparable to their knowledge score. Mean attitude and the behaviour score of this study was 65.7 and 66.1 respectively. There was significant correlation between their attitude and behaviour scores.

Majority (about $90 \%, \mathrm{n}=345$ ) of mothers agreed to see a doctor for neonatal jaundice within a period less than 24 hours. Majority (about 80\%, n=307) agreed for testing.

Our study demonstrated that the majority of mothers $(n=328)$ did not consider any special food or any type of Ayurvedic treatment as self- remedies for neonatal jaundice. About $80 \%$ of mothers $(n=309)$ agreed for phototherapy which is good compared to other studies ${ }^{6,7}$. About $52 \%$ of mothers $(n=198)$ in our study came to know about phototherapy from midwifes and $12 \%(n=46)$ learnt about it from other pregnant mothers. It is interesting that majority of the mothers $(n=326)$ sought medical advice without any delay. About $15 \%$ mothers $(n=58)$ in this study initially postponed the medical consultation due to 
constraints of hospitalization and observing the baby at home.

\section{Conclusions}

- Knowledge of neonatal jaundice among postnatal mothers was low and this was significantly associated with educational level and ethnicity.

- There was a significant correlation of mothers' attitude and behaviour scores with the knowledge scores.

\section{Recommendation}

It is recommended that issues related to neonatal jaundice should be further addressed at the community level and existing maternal health services strengthened on all aspects of neonatal jaundice.

\section{Acknowledgements}

We thank Dr. Kalyani Pethiyagoda, Senior Lecturer, Community Medicine Department, Medical Faculty Peradeniya and Dr. Sujith Ekanayaka, Medical Officer, Tele Medicine Unit, Provincial Hospital, Badulla for statistical analysis and interpretation of results. We greatly appreciate the kind co-operation and assistance of Sanjeewa and Nilanthi from Tele Medicine Unit. We thank the Director, Consultants and the staff of Wards 16 and 17 of Provincial General Hospital, Badulla for their support in conducting this survey. We are grateful to the postnatal mothers who participated in this study.

\section{References}

1. Andreoli TE, Carpenter CCJ. Cecil Essentials of Medicine. $5^{\text {th }}$ ed. Philadelphia: W.B. Saunders; 2001. p 371-2.
2. Behrman R, Kliegman $\mathrm{R}$, Jenson $\mathrm{H}$, editors. Nelson Text book of Paediatrics. $17^{\text {th }}$ ed. Philadelphia: W.B. Saunders; 2004, p 523-99.

3. Chappjumbo AUN, Ohanenye C. Awareness of neonatal jaundice among women seen at an immunization clinic in Aba. Journal of Medical Investigation and Practice 2008; 7; 66-70.

4. Ogunfowora OB, Daniel OJ. Neonatal jaundice and its management: Knowledge, attitude and practice of community health workers in Nigeria. BMC Public Health 2006; 6:19. http://dx.doi.org/10.1186/1471-2458-6-19

5. Jamison DT, Breman JG, Measham AR, Alleyne G, Claeson M, Evans DB, Jha P, Mills A, Musgrove $\mathrm{P}$, editors. Priorities in health: Disease control priorities project. Washington DC: World Bank; 2006.

6. Khalesi N, Rakhshani F. Knowledge, attitude and behaviour of mothers on neonatal jaundice. Journal of the Pakistan Medical Association 2008; 58: 671-4.

7. Amirshaghaghi A, Ghabili K, Shoja MM, Kooshavar H. Neonatal jaundice: Knowledge and practice of Iranian mothers with icteric newborns. Pakistan Journal of Biological Sciences 2008; 11(6): 942-5. http://dx.doi.org/10.3923/pjbs.2008.942.945

8. Hannon PR, Willis SK, Susan C, et al. Persistence of maternal concerns surrounding neonatal jaundice. Arch Pediatr Adolesc Med 2001; 155: 1357-63. 